\title{
WEIGHT STANDARDS FOR MEN AND WOMEN
}

$\mathrm{I}^{\mathrm{N}}$ Niew of the importance of body-weight to health and longevity, the findings of the Build and Blood Pressure Study, 1959, conducted by the Society of Actuaries of the United States, are of major significance (Metropolitan Life Insurance Co. Statistical Bulletin, Vol. 40 (November-December 1959) : New Weight Standards for Men and Women. Fathers are Younger. How Fatal Accidents Occur in the Home. Geographic Variations in Mortality by Cause. Pp. 12. New York: Metropolitan Life Insurance Company, 1959). The study not only contributes new data on average heights and weights according to age but also provides information from which new standards of desirable weight have been developed by the Statistical Bureau of the Metropolitan Life Insurance Co.

The new tables of average weights differ from those which were based on two similar studies of insured persons covering the periods $1885-1900$ and $1909-27$. For women the new average weights are consistently less than they were in the earlier studies, while for men they tend to be higher than before. Thus, at age 25 , the average weight for women is generally 5 to 6 pounds less than that shown in the last study; at the age 35 it is from 2 to 4 pounds less, and at age 45 generally 2 to 3 pounds less. The decrease in average weights of women reflects chiefly their efforts to keep shim and, to some extent, the lighter weight of their clothes. Among men, the increase in average weight, compared with earlier studies, varies appreciably with height. The increase is greatest for short men, amounting to 5 pounds or more at most ages. For men of average height the increase is from 2 to 4 pounds, and for tall men from 1 to 3 pounds, the larger differences being found below the age of 45 .

The average weights in the present study rise with advance in age among both men and women, but the pattern differs somewhat for the two sexes. Among men, the averages rise rapidly during the twenties and early thirties, but the rate of increase then slackens off and is very small between the forties and fifties. Among women, the increases in weight with age are fairly steady, but are most rapid between the mid-thirties and mid-forties. The lowest mortality generally occurs among people who are well below average weight. Even among young people, the advantage of a slight degree of over-weight is less pronounced than in earlier studies, and at best can now be considered only a temporary advantage. At the middle and older ages, the results of the new study not only show the disadvantage of over-weight, but also indicate that desirable weights, under current conditions, are somewhat lower than those shown in the tables prepared by the Metropolitan Life Insurance Co. in the early 1940's.

\section{TEMPERATURE CHANGES IN THE ANTARCTIC ATMOSPHERE}

$\mathrm{D}_{\text {has }}^{\mathrm{n}}$ R. H. WEXLER, chief scientist of the U.S.International Geophysical Year Programme, has published a valuable paper on the subject of seasonal and other temperature changes in the Antarctic atmosphere in the July 1959 issue of the Quarterly Journal of the Royal Meteorological Society. His results are based on observations made at U.S. and British International Geophysical Year stations in Antarctica and by the Scandinavian-British expedition to Maudheim during 1950-51.

The variation of temperature with height of the seasonal changes is strikingly different from that over temperate continents. The seasonal changes over Antarctica are greatest in the stratosphere (50-60 deg. C.), moderate at the surface (20-40 deg. C.), and least in the troposphere $(10 \mathrm{deg}$. C.). The effect of the greater cooling of the stratosphere is to destroy for a long period the normal sharp inversion boundary of the tropopause between troposphere and stratosphere. During the sunlit part of the year the stratosphere is heated directly by absorption of solar radiation by the ozone which it contains, and it is cooled during the dark part by loss of heat by radiation from the ozone, carbon dioxide and water vapour, so that the stratospheric temperature falls quickly in autumn and rises very rapidly in spring. The fall of surface temperature is rapid in the autumn as the snow surface cools by radiation. Cloud in the winter causes remarkable increases in surface temperature since it is at a higher temperature than the surface itself and so heats the surface by radiation. An example of an increase of temperature by $30 \mathrm{deg}$. F. in $24 \mathrm{hr}$. at the South Pole when cirrus cloud came over is described in some detail. In the summer the snow surface is warmed by solar radiation despite its high albedo. The small temperature change in the troposphere is ascribed to the horizontal influx of warm air from over the surrounding ocean. Reasons are given as to why such advection does not reduce the temperature change in the stratosphere. In the troposphere, and at the surface, there is no marked minimum of temperature a month or so after the winter solstice as there is in temperate latitudes. In Antarctica the temperature drops sharply in autumn and then fluctuates about a low mean until the spring, when it rises sharply again.

The year to year temperature changes in Antaretica are as large as those in the interiors of a continent of the temperate zone, amounting to more than $10 \mathrm{deg}$. C. in the winter months. Thus, in August 1958 Byrd station in West Antarctica was $13 \mathrm{deg}$. C. colder than in August 1957.

By comparing recent observations on the Ross Ice Shelf with earlier ones as far back as those of Amundsen in 1911-12, Wexler is able to deduce the secular change of temperature. It is found that the mean annual temperature has risen by $2 \cdot 6 \mathrm{deg}$. C. since 1911 , which compares with a rise of $6 \cdot 2 \mathrm{deg}$. C. at Spitsbergen over the same period. 